\title{
Antioxidant and antidiabetic properties of tartary buckwheat rice flavonoids after in vitro digestion*
}

\author{
Tao $\mathrm{BAO}^{\S 1}$, Ye WANG ${ }^{\S 3}$, Yu-ting $\mathrm{LI}^{1}$, Vemana GOWD ${ }^{1}$, Xin-he NIU ${ }^{3}$, \\ Hai-ying $\mathrm{YANG}^{3}$, Li-shui $\mathrm{CHEN}^{3}$, Wei CHEN ${ }^{\dagger 1}$, Chong-de SUN ${ }^{\dagger \dagger 2}$ \\ ( ${ }^{1}$ Department of Food Science and Nutrition, Zhejiang Key Laboratory for Agro-Food Processing, Zhejiang University, Hangzhou 310058, China) \\ $\left({ }^{2}\right.$ Laboratory of Fruit Quality Biology, Zhejiang Provincial Key Laboratory of Horticultural Plant Integrative Biology, the State Agriculture Ministry \\ Laboratory of Horticultural Plant Growth, Development and Quality Improvement, Zhejiang University, Hangzhou 310058, China) \\ $\left({ }^{3}\right.$ Nutrition and Health Research Institute, COFCO Ltd., Beijing 102209, China) \\ †E-mail: zjuchenwei@zju.edu.cn; adesun2006@zju.edu.cn \\ Received May 30, 2016; Revision accepted Sept. 30, 2016; Crosschecked Nov. 10, 2016
}

\begin{abstract}
Oxidative stress and diabetes have a tendency to alter protein, lipid, and DNA moieties. One of the strategic methods used to reduce diabetes-associated oxidative stress is to inhibit the carbohydrate-digesting enzymes, thereby decreasing gastrointestinal glucose production. Plant-derived natural antioxidant molecules are considered a therapeutic tool in the treatment of oxidative stress and diabetes. The objective of this study was to identify tartary buckwheat rice flavonoids and evaluate the effect of in vitro digestion on their antioxidant and antidiabetic properties. High performance liquid chromatography (HPLC) analysis indicated the presence of rutin as a major component and quercitrin as a minor component of both digested and non-digested flavonoids. Both extracts showed a significant antioxidant capacity, but digested flavonoids showed reduced activity compared to non-digested. There were some decreases of the antioxidant activities (2,2'-azino-bis-(3-ethylbenzthiazoline-6-sulfonic acid) diammonium salt (ABTS), 2,2-diphenyl-1-picrylhydrazy (DPPH) radical, and ferric reducing antioxidant power (FRAP)) of digested tartary buckwheat rice flavonoids compared with non-digested. Flavonoids from both groups significantly inhibited reactive oxygen species (ROS) production and $\alpha$-glucosidase activity. Both digested and non-digested flavonoids markedly increased glucose consumption and glycogen content in HepG2 cells. Tartary buckwheat rice flavonoids showed appreciable antioxidant and antidiabetic properties, even after digestion. Tartary buckwheat rice appears to be a promising functional food with potent antioxidant and antidiabetic properties.
\end{abstract}

Key words: Tartary buckwheat rice, Flavonoids, In vitro digestion, Antioxidant activity, Antidiabetic activity http://dx.doi.org/10.1631/jzus.B1600243

CLC number: TQ041+.8; TS213

\section{Introduction}

Oxidative stress instigated by reactive oxygen species (ROS) leads to mutations and DNA damage (Chen et al., 2015), which further leads to the devel-

\footnotetext{
${ }^{\ddagger}$ Corresponding authors

$\S$ The two authors contributed equally to this work

* Project supported by the Beijing Municipal Science and Technology Plan (No. D151100004015002) and the Research Foundation of the Education Department of Zhejiang Province (No. Y201328143), China (D) ORCID: Wei CHEN, http://orcid.org/0000-0002-2373-2437

(C) Zhejiang University and Springer-Verlag Berlin Heidelberg 2016
}

opment of chronic disorders and age-related diseases (Khansari et al., 2009; Klaunig et al., 2010; Chen et al., 2012b; Rahman et al., 2012). Oxidative stressinduced cellular dysfunction occurs when endogenous antioxidant defence mechanisms and DNA repair systems are overwhelmed. Hence, oxidative stress plays a critical role in the manifestation of micro- and macro-complications of diabetes by modifying protein, lipid, and DNA moieties (Giacco and Brownlee, 2010; Su et al., 2016). Diabetes is characterised by an increase in blood glucose (Gowd and Nandini, 2015) 
and is associated with multiple etiologies including interruptions to carbohydrate, fat, and protein metabolism (Liu et al., 2013). Diabetes can be managed by reducing oxidative stress. Antioxidants are known to reduce the complications of diabetes induced by oxidative stress by delaying glucose absorption. This is achieved by inhibiting carbohydrate hydrolyzing enzymes such as $\alpha$-amylase and $\alpha$-glucosidase (Yu et al., 2012; Alakolanga et al., 2015). $\alpha$-Amylase, a primary enzyme mostly found in the saliva, is capable of decomposing starch into absorbable molecules (Kim et al., 2014). $\alpha$-Glucosidase is located in the mucosal brush border and helps the digestion of oligosaccharides to monosaccharides (Hlila et al., 2015).

There is increasing interest in finding enzyme inhibitors which delay carbohydrate breakdown and eliminate the postprandial peak in blood glucose (Kwon et al., 2007). Studies have shown that most natural antioxidants can enhance the action of defence systems against oxidative stress and the management of postprandial hyperglycaemia by inhibiting primary carbohydrate hydrolyzing enzymes such as $\alpha$-amylase and $\alpha$-glucosidase (Hashim et al., 2013). Due to the presence of a wide range of bioactive compounds with potent antioxidant (Chen et al., 2011; 2013a) and antidiabetic properties (Khansari et al., 2009; Hashim et al., 2013), plant products are of great interest.

Tartary buckwheat (TBW), Fagopyrum tataricum, a member of the Polygonaceae, is found all over the world, especially in China and Russia (Li and Zhang, 2001). Globally, it is used as a human dietary supplement in a form of bran, groats, and flour. TBW is also used as a substitute for rice in some parts of the world and especially in China. Extensive research has reported the potential health benefits of buckwheat, especially its use in Chinese traditional medicine against various cancers (Zhou et al., 2012). Consumption of buckwheat and buckwheat-enriched diets is associated with a myriad of biological activities, such as antidiabetic (Lee et al., 2007; Hosaka et al., 2011), anti-hypercholesterolemic (Choi et al., 2007), anti-oxidative, anti-hypertensive (Merendino et al., 2014), anti-cancer, and anti-inflammatory properties (Lee et al., 2013; Zhu, 2016). Researchers have speculated that these properties could be linked to the potential antioxidant activity of compounds in such diets. Oxidative stress is notorious for its decisive role in the development of various kinds of metabolic disorders and other degenerative diseases. The antioxidant capacity of buckwheat has been widely studied (Kreft, 2016). Flavonoids in buckwheat have been shown to reduce high glucose-induced oxidative stress. Supplementation of hepatic cells with TBW flavonoids provided protection against high glucoseinduced oxidative stress and insulin resistance via MAPK signalling (Hu et al., 2016). In another study, supplementation with buckwheat honey protected DNA and reduced liver damage induced in mice by carbon tetrachloride (Cheng et al., 2015). Supplementation with buckwheat honey also resulted in strong 2,2-diphenyl-1-picrylhydrazy (DPPH) radical scavenging activity and potential ferric reducing antioxidant activity, and enhanced hepatic antioxidant enzymes such as superoxide dismutase and glutathione peroxidase (Cheng et al., 2015). Most bioactive compounds undergo extreme gastrointestinal digestion before exerting their biological activity. Some studies have shown an increase in the biological activity of compounds subjected to in vitro digestion (Chen et al., 2016a; 2016b).

Although belonging to the same species, different forms of buckwheat may contain different bioactive compounds with variable potency. Most forms of buckwheat have been extensively studied, but there have been no studies of TBW rice, which is widely used as a functional food in the Yunnan and Sichuan Provinces and other parts of China. Therefore, in this study, we chose to assess the impact of in vitro simulated digestion on the content and antioxidant and antidiabetic properties of flavonoids in TBW rice.

\section{Materials and methods}

\subsection{Materials and regents}

TBW rice was purchased from the Kunming Dianqiao Food Co., Ltd. (Yunnan, China). The samples were stored in a cool and dark place. 2,2'-Azino-bis-(3-ethylbenzthiazoline-6-sulfonic acid) diammonium salt (ABTS), DPPH, 6-hydroxy-2,5,7,8tetramethylchroman-2-carboxylic acid (Trolox), rutin, quercitrin $\alpha$-glucosidase, $p$-nitrophenol glucopyranoside ( $p$ NPG), 3-(4,5-dimethyl-2-thiazolyl)-2,5-diphenyl-2H-tetrazolium bromide (MTT), 2',7'-dichlorofluorescein 
diacetate (DCFH-DA), pepsin, pancreatin, and bile salts were obtained from Sigma-Aldrich (St. Louis, MO, USA). Vitamin C, bovine serum albumin (BSA), and anthrone were purchased from the Aladdin Reagent Co., Ltd. (Shanghai, China). Glucose assay kits were purchased from the Nanjing Jiancheng Bioengineering Institute (Nanjing, China). All other reagents used were of analytical grade.

\subsection{Extraction of flavonoids from TBW rice}

Two hundred grams of TBW rice was firstly ground to a powder. Then, $5 \mathrm{~g}$ of the powder was accurately weighed and extracted with $120 \mathrm{ml}$ of ethanol-water $(60 \%, \mathrm{v} / \mathrm{v})$ at $70{ }^{\circ} \mathrm{C}$ for $60 \mathrm{~min}$. The extraction process was repeated twice. The flavonoid extract was centrifuged at $4000 \mathrm{r} / \mathrm{min}$ for $10 \mathrm{~min}$. After centrifugation, the supernatant was collected and subjected to evaporation at $40{ }^{\circ} \mathrm{C}$ to remove ethanol. The remaining fluid was subjected to lyophilization for $48 \mathrm{~h}$. The lyophilized powder (LP) sample of TBW rice flavonoid extract (TBFE) was stored at $-80{ }^{\circ} \mathrm{C}$ for further analysis.

\subsection{In vitro digestion}

To assess the influence of simulated digestion on TBW rice flavonoids and their biological activity, the flavonoid extract was subjected to simulated in vitro digestion as described previously, with slight modification (Chen et al., 2016a). Briefly, $100 \mathrm{mg}$ of TBFE was dissolved in $10 \mathrm{ml}$ of distilled water. Porcine pepsin $(3000 \mathrm{U} / \mathrm{mg}, 20 \mathrm{mg})$ was added to the mixture, which was then adjusted to $\mathrm{pH} 2.0$ with $1 \mathrm{~mol} / \mathrm{L} \mathrm{HCl}$. Then the sample was incubated at $37^{\circ} \mathrm{C}$ in a shaking water bath for $1 \mathrm{~h}$ at $100 \mathrm{r} / \mathrm{min}$. The $\mathrm{pH}$ was adjusted to 6.0 with $1 \mathrm{~mol} / \mathrm{L}$ sodium bicarbonate, and then $20 \mathrm{mg}$ of pancreatin and $120 \mathrm{mg}$ of bile salts were added. The mixture was adjusted to $\mathrm{pH} 7.5$ with $1 \mathrm{~mol} / \mathrm{L}$ sodium hydroxide and incubated at $37^{\circ} \mathrm{C}$ in a shaking water bath for $2 \mathrm{~h}$ at $100 \mathrm{r} / \mathrm{min}$. After incubation, the digested sample was centrifuged at $8000 \mathrm{r} / \mathrm{min}$ for $10 \mathrm{~min}$. The supernatant was collected and made up to a final concentration of $6 \mathrm{mg} \mathrm{TBFE} / \mathrm{ml}$ by diluting with distilled water. The TBW rice flavonoid extract digest (TBFD) was stored at $-80^{\circ} \mathrm{C}$ for further investigation.

\subsection{Identification of flavonoids by HPLC}

Flavonoid compounds of TBW rice (digested and non-digested) were analyzed using a high per- formance liquid chromatography (HPLC) system (Waters, USA) with a diode array detector. The column was Promosil C18 $(4.6 \mathrm{~mm} \times 250 \mathrm{~mm}, 5 \mu \mathrm{m})$ operated at $30{ }^{\circ} \mathrm{C}$. The mobile phase consisted of solvent A (water and formic acid, 98.5/1.5, v/v) and solvent B (formic acid, acetonitrile, methanol, and water, 1.5:22.5:22.5:48.5, v/v/v/v). The flow rate was set at $1.0 \mathrm{ml} / \mathrm{min}$ and the injection volume was $10 \mu \mathrm{l}$. A linear gradient program was applied as follows: 0-35 min from $93 \%$ to $75 \%$ (A), 35-45 min from $75 \%$ to $35 \%$ (A), $45-46 \mathrm{~min}$ from $35 \%$ to $0 \%$ (A), $46-50 \mathrm{~min} 0 \%$ (A), $50-57 \mathrm{~min}$ from $0 \%$ to $93 \%$ (A), then $93 \%$ (A) for $3 \mathrm{~min}$. The spectra of flavonoid compounds were recorded at $360 \mathrm{~nm}$. Rutin and quercitrin were used as standards.

\subsection{Antioxidant assay}

\subsubsection{DPPH assay}

The free radical scavenging capacities of TBFE and TBFD were evaluated using the DPPH assay as previously described, with slight modification (Chen et al., 2014a). Briefly, $100 \mu \mathrm{l}$ of TBFE or TBFD was added to $500 \mu \mathrm{l}$ of a $0.1 \mathrm{mmol} / \mathrm{L}$ solution of DPPH in ethanol and incubated in darkness at room temperature for $30 \mathrm{~min}$. After incubation, the absorbance was measured at $517 \mathrm{~nm}$. The percentage inhibition of DPPH radicals caused by TBFE and TBFD was determined according to the following formula:

$$
\text { Inhibition rate }=\left[\left(A_{\text {control }}-A_{\text {sample }}\right) / A_{\text {control }}\right] \times 100 \% \text {, }
$$

where $A_{\text {control }}$ and $A_{\text {sample }}$ are the absorbances of the control and sample, respetively. Ascorbic acid was used as an antioxidant standard.

\subsubsection{ABTS assay}

The ABTS radical cation $\left(\mathrm{ABTS}^{\circ+}\right)$ assay (Floegel et al., 2011) was used to evaluate the radical scavenging activities of TBFE and TBFD, with slight modifications. Briefly, ABTS $^{\cdot+}$ stock solution was prepared by reacting $10 \mathrm{ml}$ of $7 \mathrm{mmol} / \mathrm{L} \mathrm{2,2'-azobis}$ (2-amidinopropane) dihydrochloride with $179 \mathrm{ml}$ of $140 \mathrm{mmol} / \mathrm{L}$ aqueous potassium persulfate. The mixture was incubated for $12 \mathrm{~h}$ at room temperature in darkness. A working solution of $\mathrm{ABTS}^{*+}$ was made by diluting the stock solution 20 -fold with phosphate buffer saline (PBS) for further use. Six hundred microliters of $\mathrm{ABTS}^{\circ+}$ solution were mixed with $20 \mu \mathrm{l}$ of 
TBFE or TBFD at different concentrations and, after incubation for $6 \mathrm{~min}$ in the dark, the decrease in absorbance at $734 \mathrm{~nm}$ was monitored. The $\mathrm{ABTS}^{\circ+}$ radical scavenging activities of TBFE and TBFD are expressed as mg vitamin $\mathrm{C}$ equivalent (VCE)/g LP sample.

\subsubsection{FRAP assay}

The ferric reducing antioxidant power (FRAP) assay (Chen et al., 2013a) was used to assess the ferric reducing activities of TBFE and TBFD. Ten milliliter of $10 \mathrm{mmol} / \mathrm{L}$ 2,4,6-tripyridyl-S-triazine (TPTZ) solution, $10 \mathrm{ml}$ of $20 \mathrm{mmol} / \mathrm{L} \mathrm{FeCl}_{3}$, and $100 \mathrm{ml}$ of $300 \mathrm{mmol} / \mathrm{L}$ acetate buffer $(\mathrm{pH} \mathrm{3.5})$ were mixed to produce a FRAP working solution. Fifty microliters of TBFE or TBFD were mixed with $500 \mu \mathrm{l}$ of FRAP solution. The mixture was then incubated at $37{ }^{\circ} \mathrm{C}$ for $30 \mathrm{~min}$, and the absorbance was measured at $593 \mathrm{~nm}$. Vitamin $\mathrm{C}$ was used as an antioxidant standard.

\section{$2.6 \alpha$-Glucosidase inhibitory assay}

The a-glucosidase inhibitory assay was adapted according to a previously described method (YilmazerMusa et al., 2012). Briefly, $5 \mu \mathrm{l}$ of the $\alpha$-glucosidase solution $(5 \mathrm{U} / \mathrm{ml}$, dissolve in $0.1 \mathrm{~mol} / \mathrm{L}$ potassium phosphate buffer, $\mathrm{pH}$ 6.9) was added to $20 \mu \mathrm{l}$ of sample solution at different concentrations and made up to $500 \mu \mathrm{l}$ with $0.1 \mathrm{~mol} / \mathrm{L}$ potassium phosphate buffer ( $\mathrm{pH}$ 6.9). The reaction mixture was incubated at $37{ }^{\circ} \mathrm{C}$ for $20 \mathrm{~min}$. The reaction was then initiated by adding $10 \mu \mathrm{l}$ of $p$ NPG $(10 \mathrm{mmol} / \mathrm{L})$ as substrate and the mixture was incubated at $37^{\circ} \mathrm{C}$ for $30 \mathrm{~min}$. Finally, the reaction was terminated by the addition of $500 \mu \mathrm{l}$ of $1 \mathrm{~mol} / \mathrm{L} \mathrm{Na}_{2} \mathrm{CO}_{3}$. Absorption was measured at $405 \mathrm{~nm}$, and inhibitory activity was calculated using Eq. (1).

\subsection{Cell culture}

Human HepG2 cells were obtained from the Cell Bank of Type Culture Collection of the Chinese Academy of Sciences (Shanghai, China). Cells were cultured as previously described (Chen et al., 2014b). Briefly, HepG2 cells were cultured in Dulbecco's modified Eagle's medium (DMEM) containing 10\% $(\mathrm{v} / \mathrm{v})$ fetal calf serum, $100 \mathrm{U} / \mathrm{ml}$ penicillin, and $100 \mathrm{U} / \mathrm{ml}$ streptomycin at $37{ }^{\circ} \mathrm{C}$, with $5 \% \mathrm{CO}_{2}$ in a humidified incubator.

\subsection{Cell viability assay}

Cell viability was determined using the MTT method as previously described (Chen et al., 2013b). Briefly, the cells were seeded into 96-well culture plates at a density of $5 \times 10^{3}$ cells/well and incubated for $24 \mathrm{~h}$. After incubation, the cells were treated with TBFE and TBFD at different concentrations for $24 \mathrm{~h}$. The medium was then removed and MTT $(0.5 \mathrm{mg} / \mathrm{ml})$ was added to each well and the plates were incubated for $4 \mathrm{~h}$. The formazan precipitate was dissolved by the addition of $150 \mu \mathrm{l}$ of dimethyl sulfoxide (DMSO) to each well. Absorbance was measured at $490 \mathrm{~nm}$ using a Tecan Infinite M200 microplate reader (Molecular Devices, USA).

\subsection{Determination of cellular ROS}

Cellular ROS contents were determined as previously described, with some modification (Chen et al., 2012a). Briefly, HepG2 cells were seeded into 12 -well culture plates at a density of $5 \times 10^{5}$ cells/well. After incubation for $24 \mathrm{~h}$, cells were treated with TBFE or TBFD at different concentrations. After treatment for $24 \mathrm{~h}$, cells were incubated with $300 \mu \mathrm{mol} / \mathrm{L} \mathrm{H}_{2} \mathrm{O}_{2}$ for a further $6 \mathrm{~h}$. Cells were collected and incubated with $10 \mu \mathrm{mol} / \mathrm{L}$ DCFH-DA at $37^{\circ} \mathrm{C}$ for $30 \mathrm{~min}$, then washed with PBS and immediately analyzed using a fluorescence microscope (Nikon, Japan). The results are expressed as mean DCF fluorescence intensity calculated using the image analysis software Image-Pro Plus 6.0 (Media Cybernetics, Inc., USA), from six different microscopic fields.

\subsection{Glucose consumption}

A glucose consumption assay was used according to a previous method, with some modifications (Lv et al., 2014). Briefly, HepG2 cells were seeded into 96-cell culture plates at a concentration of $5 \times 10^{3}$ cells/well. After incubation for $24 \mathrm{~h}$, the cells were washed with PBS twice and the medium was replaced by serum-free DMEM with $0.2 \%$ BSA. The medium was then supplemented with TBFE, TBFD, or metformin $(2 \mathrm{mmol} / \mathrm{L})$. The glucose concentration in the medium was determined after $24 \mathrm{~h}$ incubation by the glucose oxidase method, using a glucose assay kit. Consumption of glucose was first calculated from the difference between the concentrations in the medium at the beginning and after an appropriate time of 
culture, and then normalized to the results of the MTT assay.

\subsection{Glycogen content}

Glycogen content was determined as previously described, with slight modification (Ouyang et al., 2011; Huang et al., 2015). Briefly, HepG2 cells were seeded into 6-well plates at a concentration of $2 \times 10^{5}$ cells/well and then treated with TBFE, TBFD, or metformin ( $2 \mathrm{mmol} / \mathrm{L})$ for $24 \mathrm{~h}$. Cells were collected and adjusted to the same concentration. The cells were then homogenized using $0.5 \mathrm{ml}$ of $30 \%$ $(0.3 \mathrm{~g} / \mathrm{ml})$ potassium hydroxide and boiled for $15 \mathrm{~min}$ to destroy glucose, followed by centrifugation at $15000 \mathrm{~g}$ for $15 \mathrm{~min}$. A volume of $1.5 \mathrm{ml}$ of ethyl alcohol was then added. The glycogen content was determined using anthrone reagent. The absorbance of the color generated by the reaction was detected at $620 \mathrm{~nm}$ and the glycogen content values were calculated using glucose as a reference standard.

\subsection{Statistical analysis}

Data are expressed as mean \pm standard deviation (SD) from at least three independent experiments. One-way analysis of variance (ANOVA) followed by multiple range significant difference (Duncan) tests $(P<0.05)$ was carried out using SPSS 22.0.

\section{Results}

\subsection{Flavonoid identification by HPLC}

TBW rice was used for the extraction of flavonoids. After ethanol-water extraction of flavonoids, the flavonoid extract of TBW rice was subjected to simulated in vitro digestion to find the impact of in vitro digestion on flavonoids and their biological activity. The types and concentrations of TBFD and TBFE were determined by HPLC. HPLC analysis showed the presence of rutin in a major proportion, while a small amount of quercitrin was detected. The retention time of rutin and quercitrin was 48.823 and $49.480 \mathrm{~min}$, respectively, in TBFE (Fig. 1a) and 48.813 and $49.470 \mathrm{~min}$, respectively, in TBFD (Fig. 1b). A slight decrease in the amount of rutin and quercitrin was found in TBFD compared to TBFE. The amounts of rutin in TBFE and TBFD were $46.42 \mathrm{mg} / 100 \mathrm{mg}$ LP (LP of TBW rice flavonoid) and $43.42 \mathrm{mg} / 100 \mathrm{mg} \mathrm{LP}$, respectively, and the amounts of quercitrin in TBFE and TBFD were $6.43 \mathrm{mg} / 100 \mathrm{mg}$ LP and $5.74 \mathrm{mg} / 100 \mathrm{mg}$ LP, respectively (Table 1).

\subsection{Antioxidant activities of TBFE and TBFD}

After quantitative determination of flavonoid concentrations, antioxidant assays (ABTS, DPPH, and FRAP) were performed to evaluate the antioxidant

(a)

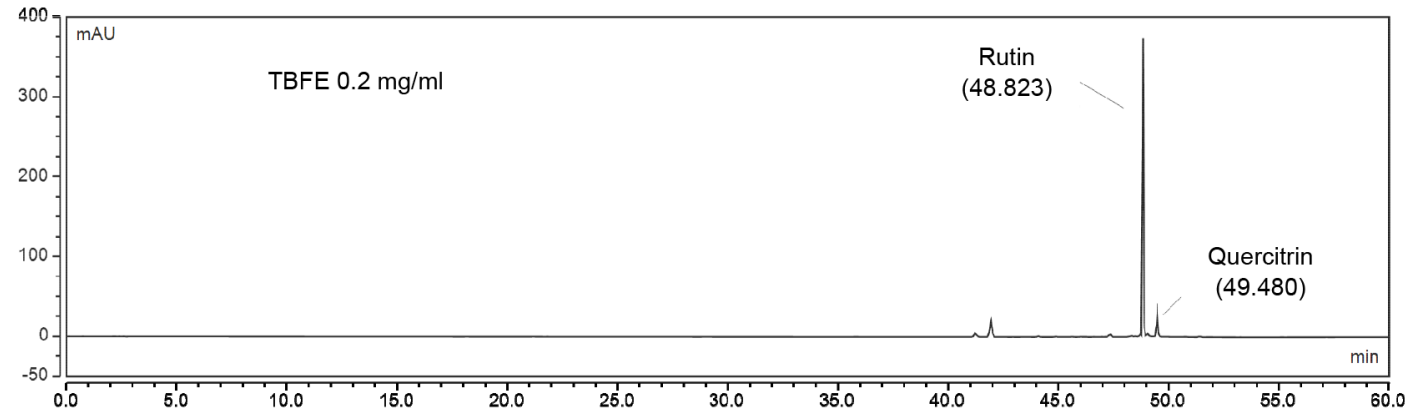

(b)

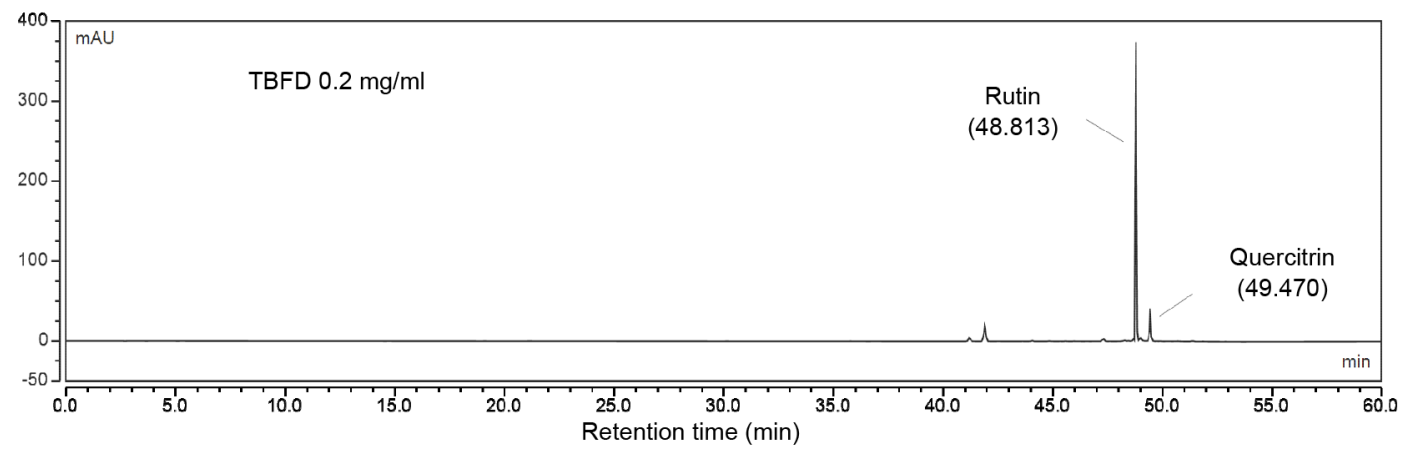

Fig. 1 HPLC-ultra violet (UV) chromatograms of flavonoids in tartary buckwheat rice flavonoid extract (TBFE) (a) and tartary buckwheat rice flavonoid extract digest (TBFD) (b) 
Table 1 Flavonoid contents of tartary buckwheat rice flavonoid extract (TBFE) and tartary buckwheat rice flavonoid extraction digest (TBFD)

\begin{tabular}{ccc}
\hline Content & Rutin (mg/100 mg LP) & Quercitrin (mg/100 mg LP) \\
\hline TBFE & $46.42 \pm 0.41$ & $6.43 \pm 0.07$ \\
TBFD & $43.42 \pm 0.32$ & $5.74 \pm 0.08$
\end{tabular}

LP: lyophilized powder. The values are expressed as mean $\pm \mathrm{SD}(n=3)$

activities of TBFE and TBFD. The results are presented in Table 2. According to the ABTS assay, the antioxidant activities of TBFE and TBFD showed a concentration-dependent response (Fig. 2a). The antioxidant activities of TBFE and TBFD (ABTS assay) were 101.87 and $63.57 \mathrm{mg} \mathrm{VCE} / \mathrm{g} \mathrm{LP}$, respectively. The DPPH radical scavenging activities of TBFE and TBFD were 110.80 and $46.24 \mathrm{mg}$ VCE/g LP, respectively. Both TBFE and TBFD showed a significant free radical scavenging activity against DPPH free radicals in a concentration-dependent response (Fig. 2b). Furthermore, the antioxidant activities of TBFE and TBFD according to the FRAP assays were 19.37 and $7.00 \mathrm{mg} \mathrm{VCE} / \mathrm{g}$ LP, respectively. These results indicate that both TBFE and TBFD have a potent antioxidant capacity and also suggest that flavonoids exhibit potential antioxidant activity even after digestion.

Table 2 In vitro antioxidant activity and enzyme inhibition activity of tartary buckwheat rice flavonoid extract (TBFE) and tartary buckwheat rice flavonoid extract digest (TBFD)

\begin{tabular}{|c|c|c|c|c|}
\hline \multirow[t]{2}{*}{ Sample } & \multicolumn{3}{|c|}{$\begin{array}{l}\text { Antioxidant activity } \\
\text { (mg VCE/g LP) }\end{array}$} & \multirow{2}{*}{$\begin{array}{l}\text { Inhibition activity of } \\
\alpha \text {-glucosidase, } \mathrm{IC}_{50} \\
(\mathrm{mg} / \mathrm{ml})\end{array}$} \\
\hline & ABTS & DPPH & FRAP & \\
\hline TBFE & 101.87 & 110.80 & 19.37 & 0.31 \\
\hline TBFD & 63.57 & 46.24 & 7.00 & 0.42 \\
\hline Acarbose & & & & 0.25 \\
\hline
\end{tabular}

VCE: vitamin C equivalent; LP: lyophilized powder; $\mathrm{IC}_{50}: 50 \%$ inhibition

(a)

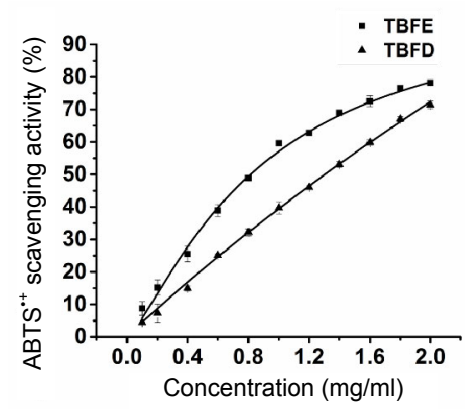

\subsection{Intracellular ROS scavenging capacities of TBFE and TBFD}

The cytotoxicities of TBFE and TBFD were evaluated in HepG2 cells using the MTT method, prior to analysis of their ROS scavenging capacities. Treatment of HepG2 cells with TBFE or TBFD for $24 \mathrm{~h}$ did not induce any remarkable changes up to $100 \mu \mathrm{g} / \mathrm{ml}$. However, a decrease in cell viability was observed at $200 \mu \mathrm{g} / \mathrm{ml} \mathrm{TBFD} \mathrm{(Fig.} \mathrm{3a).} \mathrm{Metformin} \mathrm{at}$ $2 \mathrm{mmol} / \mathrm{L}$ had no cytotoxic effect, indicating that it could be used as a positive control in further experiments. To assess the ROS scavenging activities of TBFE and TBFD, HepG2 cells were pre-treated with TBFE or TBFD $(10-100 \mu \mathrm{g} / \mathrm{ml})$. Then ROS were generated by exposure of cells to $\mathrm{H}_{2} \mathrm{O}_{2}$, a potential ROS generator. To evaluate the level of intracellular ROS, the fluorescence probe DCFH-DA was used. DCFH-DA is a non-fluorescent dye, which can easily penetrate cells and is hydrolysed to DCFH by intracellular esterase. DCFH would be oxidized to DCF by cellular ROS. The ROS scavenging activities of TBFE and TBFD were compared to $\mathrm{H}_{2} \mathrm{O}_{2}$ nonstimulated blanks and sample non-treated control groups. TBFE and TBFD at a concentration of $100 \mu \mathrm{g} / \mathrm{ml}$ significantly and equally inhibited ROS production (Fig. 3b). Therefore, our results indicate that flavonoids of buckwheat rice have appreciable ROS scavenging activity, even after digestion (Fig. 3c).

\section{$3.4 \alpha$-Glucosidase inhibitory activities of flavo- noids in TBFE and TBFD}

An $\alpha$-glucosidase inhibitory assay was performed to evaluate the antidiabetic properties of TBFE and TBFD. From our experimental results, we concluded that both TBFE and TBFD showed a significant inhibition of $\alpha$-glucosidase. Their inhibitory

(b)

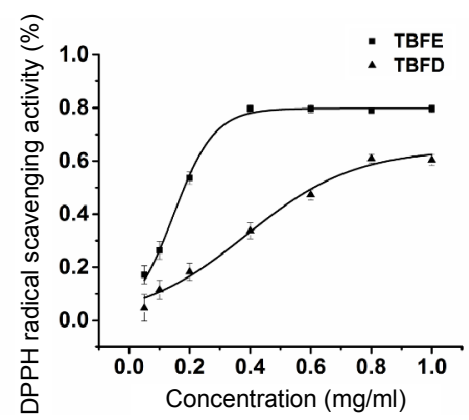

Fig. 2 Comparison of antioxidant capacities between tartary buckwheat rice flavonoid extract (TBFE) and tartary buckwheat rice flavonoid extract digest (TBFD) measured by $\mathrm{ABTS}^{++}$(a) and DPPH (b) assays The results were expressed as mean $\pm \mathrm{SD}(n=3)$ 
(a)

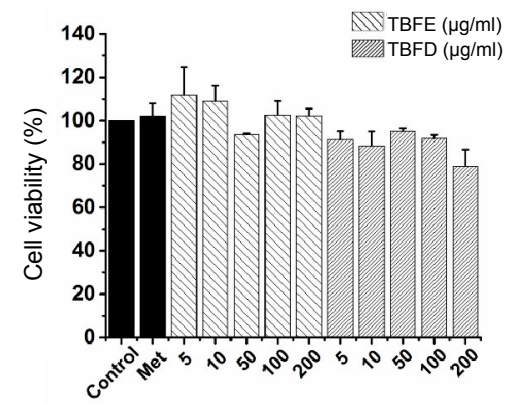

(c)

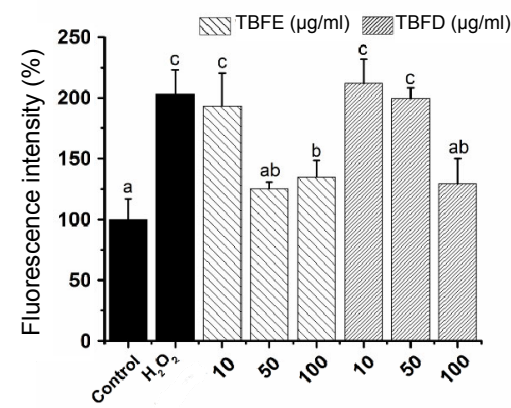

(b)
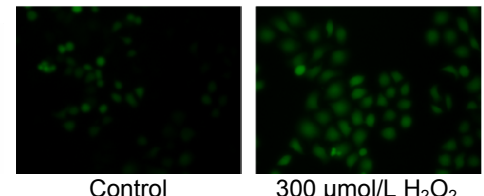

$300 \mu \mathrm{mol} / \mathrm{L} \mathrm{H}_{2} \mathrm{O}_{2}$

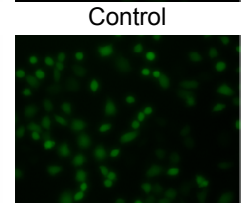

TBFE $(10 \mu \mathrm{g} / \mathrm{ml})$ $+300 \mu \mathrm{mol} / \mathrm{L} \mathrm{H}_{2} \mathrm{O}_{2}$

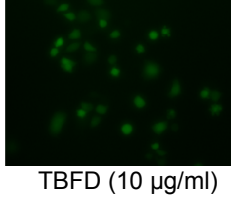

$+300 \mu \mathrm{mol} / \mathrm{L} \mathrm{H}_{2} \mathrm{O}_{2}$

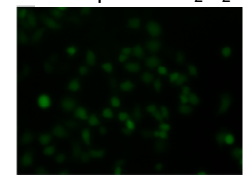

TBFE $(50 \mu \mathrm{g} / \mathrm{ml})$ $+300 \mu \mathrm{mol} / / \mathrm{L}_{2} \mathrm{O}_{2}$
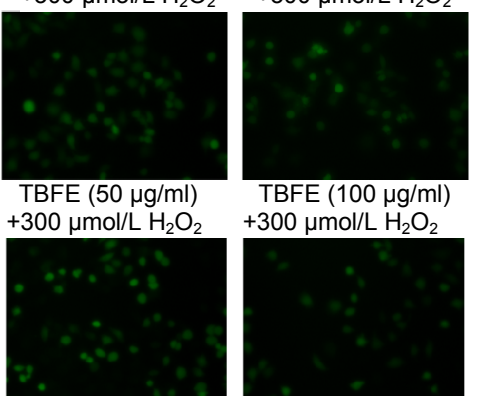

$300 \mu \mathrm{mol} / \mathrm{L} \mathrm{H}_{2} \mathrm{O}_{2}$

TBFD $(50 \mu \mathrm{g} / \mathrm{ml}) \quad$ TBFD $(100 \mu \mathrm{g} / \mathrm{ml})$

$100 \mathrm{um}+300 \mu \mathrm{mol} / \mathrm{L} \mathrm{H}_{2} \mathrm{O}_{2}+300 \mu \mathrm{mol} / \mathrm{L} \mathrm{H}_{2} \mathrm{O}_{2}$

Fig. 3 Effects of of tartary buckwheat rice flavonoid extract (TBFE) and tartary buckwheat rice flavonoid extract digest (TBFD) on $\mathrm{H}_{2} \mathrm{O}_{2}$-induced ROS in HepG2 cells

(a) Cells were treated with TBFE and TBFD at various concentrations and metformin (Met; $2 \mathrm{mmol} / \mathrm{L}$ ), and cell viability was analyzed by MTT assay. (b) Cells were treated with $300 \mu \mathrm{mol} / \mathrm{L} \mathrm{H}_{2} \mathrm{O}_{2}$ in the presence or absence of TBFE or TBFD (10, 50, or $100 \mu \mathrm{g} / \mathrm{ml}$ ) for $6 \mathrm{~h}$. Cells were collected and incubated with $10 \mu \mathrm{mol} / \mathrm{L}$ DCFH-DA at $37^{\circ} \mathrm{C}$ for $30 \mathrm{~min}$, then washed with PBS and evaluated by fluorescence microscope. (c) The results were expressed as mean DCF fluorescence intensity according to (b). Data are expressed as mean $\pm \mathrm{SD}$ of three independent experiments. Means represented with the same letters are not significantly different according to Duncan test $(P>0.05)$

effects were evaluated at different concentrations, and were shown to be concentration-dependent (Fig. 4). Based on the inhibition of $\alpha$-glucosidase at various concentrations of TBFD and TBFE, the concentration that provided $50 \%$ inhibition $\left(\mathrm{IC}_{50}\right)$ was obtained for each fraction (Table 2). The $\alpha$-glucosidase inhibitory activities of TBFE and TBFD were evaluated using acarbose (a clinical drug) $\left(\mathrm{IC}_{50}=0.25 \mathrm{mg} / \mathrm{ml}\right)$ as a positive control. According to our results, TBFE had a comparatively low $\mathrm{IC}_{50}$ value $(0.31 \mathrm{mg} / \mathrm{ml})$ compared to TBFD $\left(\mathrm{IC}_{50}=0.42 \mathrm{mg} / \mathrm{ml}\right)$. However, the flavonoids, even after digestion, had a tendency to inhibit $\alpha$-glucosidase. Such inhibition would eventually be expected to represent considerable antidiabetic activity.

\subsection{Effects of TBFE and TBFD on glucose con- sumption in HepG2 cells}

To assess the effects of TBFE and TBFD on glucose consumption, HepG2 cells were used as a model. Both TBFE and TBFD increased glucose consumption at each concentration compared to controls. However, at $10 \mu \mathrm{g} / \mathrm{ml}$, the increased glucose consumption was significantly higher (Fig. 5a).

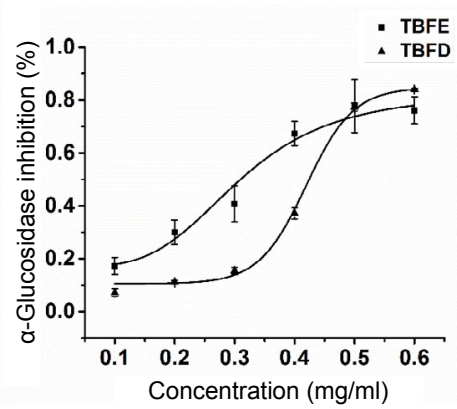

Fig. 4 Dose-dependent $\alpha$-glucosidase inhibition of tartary buckwheat rice flavonoid extract (TBFE) and tartary buckwheat rice flavonoid extract digest (TBFD) The results were expressed as mean $\pm \mathrm{SD}(n=3)$

\subsection{Effects of TBFE and TBFD on glycogen con- tent in HepG2 cells}

The glycogen content was measured in order to understand the reason for the observed increase in glucose consumption in HepG2 cells. Metformin was used as positive control to compare the effects of TBFE and TBFD. Based on the glucose consumption status of the HepG2 cells, two concentrations (10 and $50 \mu \mathrm{g} / \mathrm{ml}$ ) were selected to investigate the effects of 
(a)

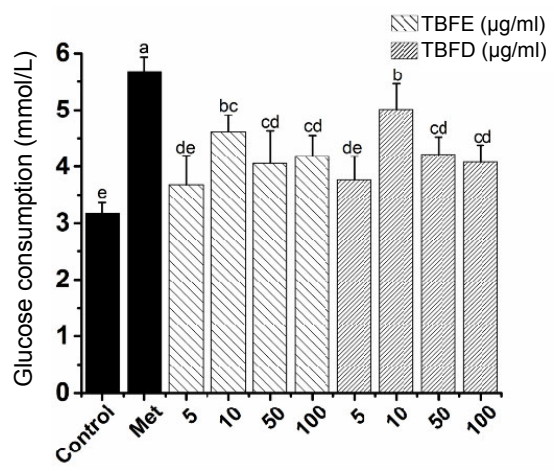

(b)

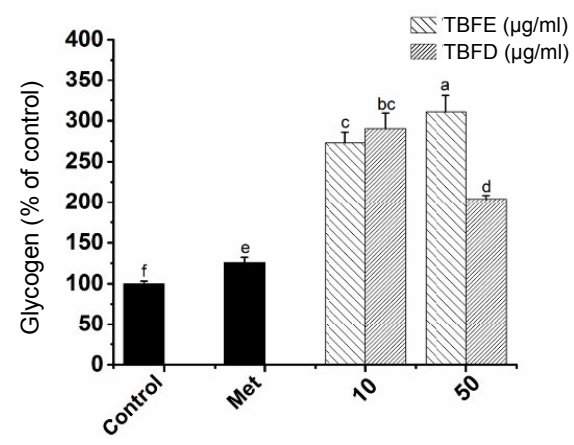

Fig. 5 Effect of of tartary buckwheat rice flavonoid extract (TBFE) and tartary buckwheat rice flavonoid extract digest (TBFD) on glucose consumption and glycogen content in HepG2 cells

(a) Effect of TBFE, TBFD, and metformin (Met; $2 \mathrm{mmol} / \mathrm{L}$ ) on glucose consumption after $24 \mathrm{~h}$ treatment of HepG2 cells; (b) Changes in the glycogen content of HepG2 cells after $24 \mathrm{~h}$ treatment of TBFE and TBFD at various concentrations and Met $(2 \mathrm{mmol} / \mathrm{L})$. The results were expressed as mean $\pm \mathrm{SD}(n=3)$. Means represented with the same letters are not significantly different according to Duncan test $(P>0.05)$

TBFE and TBFD on glycogen levels. Both TBFEand TBFD-treated cells showed an increase in glycogen content compared to control cells at both concentrations. The increase was greater than that found in metformin-treated cells (Fig. 5b).

\section{Discussion}

In this study, we evaluated the presence of flavonoids in TBW rice, which is rather different from other types of buckwheat. Buckwheat is used in diets in various forms such as groats, flour, bran, and buckwheat honey. People from the Tibet Autonomous Region of China and other parts of China use buckwheat in the form of "rice". The content and composition of the flavonoids of buckwheat vary among buckwheat species and sources such as flowers, leaves, and stems. TBW sprouts are known to show higher antioxidant activities, such as reducing power, free radical scavenging activity, and super oxide scavenging activity, than common buckwheat (Lin et al., 2008). Buckwheat sprouts are considered a functional food due to their nutritional benefits and health-promoting activities (Kim et al., 2004; Zhang et al., 2015). Some studies have suggested that the flavonoid content of buckwheat could be the reason behind its observed biological activity. Increases in the contents of rutin and quercitrin possibly have a role in the enhanced antioxidant capacity of TBW (Lin et al., 2008). In other studies, subjecting buckwheat extracts to human in vitro digestion was reported to increase antioxidant capacity via an increase in the contents of the flavonoids rutin and quercitrin (Hur et al., 2011). Therefore, in this study, a flavonoid fraction of TBW was subjected to in vitro digestion and analyzed using HPLC to evaluate the impact of in vitro digestion on flavonoids. We found no significant increase in the rutin or quercitrin content of TBW rice after digestion. In fact, we found a slight decrease in rutin and quercitrin levels. This prompted us to look into the biological activity of digested and non-digested flavonoid extracts of TBW rice.

Digested and non-digested flavonoid fractions of TBW rice were tested for their radical scavenging capacities by DPPH assay, reduction of radical cations by ABTS assay, and reduction of ferric to ferrous ions by FRAP assay. Our results indicated that the flavonoids showed potent antioxidant activity. Antioxidant activity was reduced, but still potent, after digestion. However, our results contradict those of earlier reports which found in vitro human digested buckwheat (whole grain) flavonoids showed a profound increase in antioxidant capacity (Hur et al., 2011). Comparisons of the antioxidant capacity of flavonoids such as rutin, quercitrin, and isoquercitrin of TBW suggested that quercitrin has the strongest antioxidant capacity among these three flavonoids. Flavonoid compounds of buckwheat are known to reduce the intracellular antioxidase activity, thereby increasing cellular oxidative stress. Treatment of hepatoma cells with quercitrin showed the strongest cytotoxic effect due to G2/M phase arrest accompanied by an increase in apoptotic cell death. Therefore, before testing the reactive oxygen scavenging capacities of digested and non-digested TBW rice flavonoids, different concentrations of TBFE and TBFD were tested for their effects on cell viability. 
In our study, no cytotoxicity was observed following treatment of HepG2 cells with TBW rice flavonoids (digested or non-digested). Our results indicated that digested and non-digested flavonoids showed significant ROS scavenging activity. Supplementation with buckwheat and buckwheatenriched diets is associated with multiple biological activities, such as hypoglycemic, hypercholesterolemic, anti-cancer, and anti-inflammatory effects. In other studies, germination of buckwheat seeds resulted in increased phenolic components and concomitant antioxidant capacity. Those studies recommended buckwheat as a promising functional food, and buckwheat sprouts were suggested as a new vegetable (Zhang et al., 2015; Zhou et al., 2015).

Oxidative stress is a notorious factor in the development of degenerative and age-related diseases such as diabetes (Lee et al., 2007; Hosaka et al., 2011; Yu et al., 2015), cancer (Lee et al., 2013; Zhu, 2016), immunity ( $\mathrm{Yu}$ et al., 2016), liver injury (Zhang et al., 2014; Pang et al., 2015), cardiovascular (Andriantsitohaina et al., 2012) and neurodegenerative diseases (Choi et al., 2015). Oxidative stress-induced perturbations in the antioxidant defence systems of the body lead to DNA damage and cellular dysfunction, which is further linked to diabetes. One of the strategies adopted to treat diabetes is to find novel bioactive compounds with profound antioxidant capacity. Studies of diabetes and oxidative stress revealed that molecules with potent antioxidant capacity could also inhibit carbohydrate digestive enzymes, such as $\alpha$-glucosidase and $\alpha$-amylase. High glucose-induced oxidative stress and insulin resistance were ameliorated by supplementation with TBW flavonoids in hepatic cells via MAPK signalling (Hu et al., 2016). The liver plays an important role in metabolism, with numerous functions in the human body including glucose-dependent modulation in glycogen storage, plasma protein synthesis, and detoxification. HepG2 cells are human liver cancer cells, which contain enzymes and metabolic systems similar to those of normal liver cells. HepG2 cells are frequently used as an in vitro model to study cell viability, cellular ROS, glucose consumption, and metabolism. Therefore, in this study, flavonoids of TBW rice in both forms were tested for their effects on $\alpha$-glucosidase. The flavonoids showed potent $\alpha$-glucosidase inhibition, even after digestion. Furthermore, supplementation with TBW rice flavonoids resulted in increased glucose consumption and glycogen levels in HepG2 cells. Therefore, the antioxidant activities and antidiabetic properties of TBFE and TBFD support the view that molecules with potent antioxidant capacity may also exhibit profound antidiabetic activity, even after digestion.

\section{Conclusions}

In this in vitro study, TBW rice flavonoids showed strong antioxidant activity and appreciable antidiabetic properties, even after being subject to digestion. TBW rice appears to be a promising functional food with potent antioxidant and antidiabetic properties. Based on our in vitro findings, future research could evaluate the effects of TBW rice flavonoids using in vivo models. Such research could provide strong support for developing TBW rice as a promising functional food.

\section{Compliance with ethics guidelines}

Tao BAO, Ye WANG, Yu-ting LI, Vemana GOWD, Xin-he NIU, Hai-ying YANG, Li-shui CHEN, Wei CHEN, and Chong-de SUN declare that they do not have any conflict of interest.

This article does not contain any studies with human or animal subjects performed by any of the authors.

\section{References}

Alakolanga, A., Kumar, N., Jayasinghe, L., et al., 2015. Antioxidant property and $\alpha$-glucosidase, $\alpha$-amylase and lipase inhibiting activities of flacourtia inermis fruits: characterization of malic acid as an inhibitor of the enzymes. J. Food Sci. Technol. Mys., 52(12):8383-8388. http://dx.doi.org/10.1007/s13197-015-1937-6

Andriantsitohaina, R., Auger, C., Chataigneau, T., et al., 2012. Molecular mechanisms of the cardiovascular protective effects of polyphenols. Br. J. Nutr., 108(9):1532-1549. http://dx.doi.org/10.1017/S0007114512003406

Chen, W., Li, Y., Li, J., et al., 2011. Myricetin affords protection against peroxynitrite-mediated DNA damage and hydroxyl radical formation. Food Chem. Toxicol., 49(9):2439-2444. http://dx.doi.org/10.1016/j.fct.2011.06.066

Chen, W., Feng, L., Nie, H., et al., 2012a. Andrographolide induces autophagic cell death in human liver cancer cells through cyclophilin D-mediated mitochondrial permeability transition pore. Carcinogenesis, 33(11):2190-2198. http://dx.doi.org/10.1093/carcin/bgs264

Chen, W., Feng, L., Huang, Z., et al., 2012b. Hispidin produced from phellinus linteus protects against peroxynitritemediated DNA damage and hydroxyl radical generation. Chem.-Biol. Interact., 199(3):137-142. http://dx.doi.org/10.1016/j.cbi.2012.07.001 
Chen, W., Feng, L., Shen, Y., et al., 2013a. Myricitrin inhibits acrylamide-mediated cytotoxicity in human Caco-2 cells by preventing oxidative stress. Biomed. Res. Int., 2013: 724183. http://dx.doi.org/10.1155/2013/724183

Chen, W., Zhuang, J., Li, Y., et al., 2013b. Myricitrin protects against peroxynitrite-mediated DNA damage and cytotoxicity in astrocytes. Food Chem., 141(2):927-933. http://dx.doi.org/10.1016/j.foodchem.2013.04.033

Chen, W., Shen, Y., Su, H., et al., 2014a. Hispidin derived from Phellinus linteus affords protection against acrylamide-induced oxidative stress in Caco-2 cells. Chem.-Biol. Interact., 219:83-89. http://dx.doi.org/10.1016/j.cbi.2014.05.010

Chen, W., Zhang, L., Zhang, K., et al., 2014b. Reciprocal regulation of autophagy and dntp pools in human cancer cells. Autophagy, 10(7):1272-1284.

http://dx.doi.org/10.4161/auto.28954

Chen, W., Zhou, S.M., Zheng, X.D., 2015. A new function of Chinese bayberry extract: protection against oxidative DNA damage. LWT-Food Sci. Technol., 60(2):1200-1205. http://dx.doi.org/10.1016/j.lwt.2014.09.011

Chen, W., Su, H., Xu, Y., et al., 2016a. Protective effect of wild raspberry (Rubus hirsutus Thunb.) extract against acrylamide-induced oxidative damage is potentiated after simulated gastrointestinal digestion. Food Chem., 196: 943-952.

http://dx.doi.org/10.1016/j.foodchem.2015.10.024

Chen, W., Xu, Y., Zhang, L.X., et al., 2016b. Wild raspberry subjected to simulated gastrointestinal digestion improves the protective capacity against ethyl carbamate-induced oxidative damage in Caco-2 cells. Oxid. Med. Cell. Longev., 2016:3297363. http://dx.doi.org/10.1155/2016/3297363

Cheng, N., Wu, L., Zheng, J., et al., 2015. Buckwheat honey attenuates carbon tetrachloride-induced liver and DNA damage in mice. Evid.-Based Compl. Alt., 2015:987385. http://dx.doi.org/10.1155/2015/987385

Choi, I., Seog, H., Park, Y., et al., 2007. Suppressive effects of germinated buckwheat on development of fatty liver in mice fed with high-fat diet. Phytomedicine, 14(7-8): 563-567. http://dx.doi.org/10.1016/j.phymed.2007.05.002

Choi, J.Y., Lee, J.M., Lee, D.G., et al., 2015. The $n$-butanol fraction and rutin from tartary buckwheat improve cognition and memory in an in vivo model of amyloid$\beta$-induced Alzheimer's disease. J. Med. Food, 18(6): 631-641. http://dx.doi.org/10.1089/jmf.2014.3292

Floegel, A., Kim, D.O., Chung, S.J., et al., 2011. Comparison of ABTS/DPPH assays to measure antioxidant capacity in popular antioxidant-rich US foods. J. Food Compos. Anal., 24(7):1043-1048.

http://dx.doi.org/10.1016/j.jfca.2011.01.008

Giacco, F., Brownlee, M., 2010. Oxidative stress and diabetic complications. Circ. Res., 107(9):1058-1070. http://dx.doi.org/10.1161/CIRCRESAHA.110.223545

Gowd, V., Nandini, C.D., 2015. Erythrocytes in the combined milieu of high glucose and high cholesterol shows glycosaminoglycan-dependent cytoadherence to extracellular matrix components. Int. J. Biol. Macromol., 73:182-188. http://dx.doi.org/10.1016/j.ijbiomac.2014.11.019
Hashim, A., Khan, M.S., Baig, M.H., et al., 2013. Antioxidant and $\alpha$-amylase inhibitory property of Phyllanthus virgatus L.: an in vitro and molecular interaction study. BioMed Res. Int., 2013:729393. http://dx.doi.org/10.1155/2013/729393

Hlila, M.B., Mosbah, H., Majouli, K., et al., 2015. $\alpha$-Glucosidase inhibition by Tunisian Scabiosa arenaria Forssk. extracts. Int. J. Biol. Macromol., 77:383-389. http://dx.doi.org/10.1016/j.ijbiomac.2015.03.035

Hosaka, T., Nii, Y., Tomotake, H., et al., 2011. Extracts of common buckwheat bran prevent sucrose digestion. $J$. Nutr. Sci. Vitaminol., 57(6):441-445. http://dx.doi.org/10.3177/jnsv.57.441

Hu, Y., Hou, Z., Liu, D., et al., 2016. Tartary buckwheat flavonoids protect hepatic cells against high glucoseinduced oxidative stress and insulin resistance via MAPK signaling pathways. Food Funct., 7(3):1523-1536. http://dx.doi.org/10.1039/C5FO01467K

Huang, Q., Chen, L., Teng, H., et al., 2015. Phenolic compounds ameliorate the glucose uptake in HepG2 cells' insulin resistance via activating AMPK anti-diabetic effect of phenolic compounds in HepG2 cells. J. Funct. Foods, 19:487-494. http://dx.doi.org/10.1016/j.jff.2015.09.020

Hur, S.J., Park, S.J., Jeong, C.H., 2011. Effect of buckwheat extract on the antioxidant activity of lipid in mouse brain and its structural change during in vitro human digestion. J. Agric. Food Chem., 59(19):10699-10704. http://dx.doi.org/10.1021/jf202279r

Khansari, N., Shakiba, Y., Mahmoudi, M., 2009. Chronic inflammation and oxidative stress as a major cause of age-related diseases and cancer. Recent Pat. Inflamm. Allergy Drug Discov., 3(1):73-80. http://dx.doi.org/10.2174/187221309787158371

Kim, K.T., Rioux, L.E., Turqeon, S.L., 2014. Alpha-amylase and alpha-glucosidase inhibition is differentially modulated by fucoidan obtained from Fucus vesiculosus and Ascophyllum nodosum. Phytochemistry, 98:27-33. http://dx.doi.org/10.1016/j.phytochem.2013.12.003

Kim, S.L., Kim, S.K., Park, C.H., 2004. Introduction and nutritional evaluation of buckwheat sprouts as a new vegetable. Food Res. Int., 37(4):319-327. $\mathrm{http} / / / \mathrm{dx}$.doi.org/10.1016/j.foodres.2003.12.008

Klaunig, J.E., Kamendulis, L.M., Hocevar, B.A., 2010. Oxidative stress and oxidative damage in carcinogenesis. Toxicol. Pathol., 38(1):96-109. http://dx.doi.org/10.1177/0192623309356453

Kreft, M., 2016. Buckwheat phenolic metabolites in health and disease. Nutr. Res. Rev., 29(1):30-39. http://dx.doi.org/10.1017/S0954422415000190

Kwon, Y.I., Apostolidis, E., Shetty, K., 2007. Evaluation of pepper (Capsicum annuum) for management of diabetes and hypertension. J. Food Biochem., 31(3):370-385. http://dx.doi.org/10.1111/j.1745-4514.2007.00120.x

Lee, C.C., Shen, S.R., Lai, Y.J., et al., 2013. Rutin and quercetin, bioactive compounds from tartary buckwheat, prevent liver inflammatory injury. Food Funct., 4(5):794-802. http://dx.doi.org/10.1039/c3fo30389f

Lee, Y.A., Cho, E.J., Tanaka, T., et al., 2007. Inhibitory activities of proanthocyanidins from persimmon against oxidative stress and digestive enzymes related to diabetes. J. Nutr. Sci. Vitaminol., 53(3):287-292. 
http://dx.doi.org/10.3177/jnsv.53.287

Li, S.Q., Zhang, Q.H., 2001. Advances in the development of functional foods from buckwheat. Crit. Rev. Food Sci. Nutr., 41(6):451-464. http://dx.doi.org/10.1080/20014091091887

Lin, L.Y., Peng, C.C., Yang, Y.L., et al., 2008. Optimization of bioactive compounds in buckwheat sprouts and their effect on blood cholesterol in hamsters. J. Agric. Food Chem., 56(4):1216-1223. http://dx.doi.org/10.1021/jf072886x

Liu, S., Li, D., Huang, B., et al., 2013. Inhibition of pancreatic lipase, $\alpha$-glucosidase, $\alpha$-amylase, and hypolipidemic effects of the total flavonoids from nelumbo nucifera leaves. J. Ethnopharmacol., 149(1):263-269. http://dx.doi.org/10.1016/j.jep.2013.06.034

Lv, Q., Si, M., Yan, Y., et al., 2014. Effects of phenolic-rich litchi (Litchi chinensis Sonn.) pulp extracts on glucose consumption in human HepG2 cells. J. Funct. Foods, 7: 621-629. http://dx.doi.org/10.1016/j.jff.2013.12.023

Merendino, N., Molinari, R., Costantini, L., et al., 2014. A new "functional" pasta containing tartary buckwheat sprouts as an ingredient improves the oxidative status and normalizes some blood pressure parameters in spontaneously hypertensive rats. Food Funct., 5(5):1017-1026. http://dx.doi.org/10.1039/c3fo60683j

Ouyang, J.Y., Parakhia, R.A., Ochs, R.S., 2011. Metformin activates AMP kinase through inhibition of AMP deaminase. J. Biol. Chem., 286(1):1-11. http://dx.doi.org/10.1074/jbc.M110.121806

Pang, C., Sheng, Y., Jiang, P., et al., 2015. Chlorogenic acid prevents acetaminophen-induced liver injury: the involvement of CYP450 metabolic enzymes and some antioxidant signals. J. Zhejiang Univ.-Sci. B (Biomed. \& Biotechnol.), 16(7):602-610. http://dx.doi.org/10.1631/jzus.B1400346

Rahman, T., Hosen, I., Islam, M.T., et al., 2012. Oxidative stress and human health. Adv. Biosci. Biotechnol., 3:997-1019. http://dx.doi.org/10.4236/abb.2012.327123

Su, H.M., Feng, L.N., Zheng, X.D., et al., 2016. Myricetin protects against diet-induced obesity and ameliorates oxidative stress in C57BL/6 mice. J. Zhejiang Univ.-Sci. B (Biomed. \& Biotechnol.), 17(6):437-446. http://dx.doi.org/10.1631/jzus.B1600074

Yilmazer-Musa, M., Griffith, A.M., Michels, A.J., et al., 2012. Grape seed and tea extracts and catechin 3-gallates are potent inhibitors of $\alpha$-amylase and $\alpha$-glucosidase activity. J. Agric. Food Chem., 60(36):8924-8929. http://dx.doi.org/10.1021/jf301147n

Yu, H., Zhen, J., Pang, B., et al., 2015. Ginsenoside Rg1 ameliorates oxidative stress and myocardial apoptosis in streptozotocin-induced diabetic rats. J. Zhejiang Univ.Sci. B (Biomed. \& Biotechnol.), 16(5):344-354. http://dx.doi.org/10.1631/jzus.B1400204

Yu, Z., Yin, Y., Zhao, W., et al., 2012. Anti-diabetic activity peptides from albumin against $\alpha$-glucosidase and $\alpha$-amylase. Food Chem., 135(3):2078-2085. http://dx.doi.org/10.1016/j.foodchem.2012.06.088

Yu, Z.P., Xu, D.D., Lu, L.F., et al., 2016. Immunomodulatory effect of a formula developed from American ginseng and Chinese jujube extracts in mice. J. Zhejiang Univ.-Sci. B (Biomed. \& Biotechnol.), 17(2):147.
http://dx.doi.org/10.1631/jzus.B1500170

Zhang, G., Xu, Z., Gao, Y., et al., 2015. Effects of germination on the nutritional properties, phenolic profiles, and antioxidant activities of buckwheat. J. Food Sci., 80(5): H1111-H1119. http://dx.doi.org/10.1111/1750-3841.12830

Zhang, J., Shi, L., Xu, X., et al., 2014. Therapeutic detoxification of quercetin against carbon tetrachloride-induced acute liver injury in mice and its mechanism. J. Zhejiang Univ.-Sci. B (Biomed. \& Biotechnol.), 15(12):1039-1047. http://dx.doi.org/10.1631/jzus.B1400104

Zhou, X., Wang, Q., Yang, Y., et al., 2012. Anti-infection effects of buckwheat flavonoid extracts (BWFEs) from germinated sprouts. J. Food Sci. Technol., 52(4):2458-2463. http://dx.doi.org/10.5897/JMPR11.535

Zhou, X., Hao, T., Zhou, Y., et al., 2015. Relationships between antioxidant compounds and antioxidant activities of tartary buckwheat during germination. J. Med. Plants Res., 6(1):24-29. http://dx.doi.org/10.5897/JMPR11.535

Zhu, F., 2016. Chemical composition and health effects of tartary buckwheat. Food Chem., 203:231-245. http://dx.doi.org/10.1016/j.foodchem.2016.02.050

\section{中文摘要}

\section{题 目: 体外模拟消化对黑苦莽米黄酮抗氧化及降血糖 活性的影响}

目 的: 研究黑苦菾米黄酮模拟消化前后活性成分含量 变化, 以及模拟消化对其抗氧化及降血糖活性的 影响。

创新点: 采用体外模拟消化的方法, 更加真实地反应消化 对黑苦荞米黄酮含量及活性的影响, 同时采用体 外抗氧化方法、 $\alpha$-葡萄糖苷酶实验和 HepG2 细 胞模型, 评价其抗氧化和降血糖活性。

方 法: 本文采用体外模拟消化的方法, 对黑苦养米黄酮 进行模拟消化，使用高效液相色谱（HPLC）检测 其消化前后黄酮物质含量变化情况 (表 1 和图 1); 通过 ABTS、DPPH 和 FRAP 等实验研究模拟消 化对其抗氧化活性的影响（表 2 和图 2)，进一 步检测其消化前后对细胞活性氧（ROS）产生的 抑制能力（图 3); 利用 $\alpha$-葡萄糖苷酶活性抑制 实验（图 4）以及细胞葡萄糖消耗和糖原含量实 验（图 5)，评价黑苦荞米黄酮模拟消化前后的 降血糖活性。

结 论: HPLC 结果表明, 黑苦菾米黄酮中的主要活性物 质为芦丁和檞皮苷, 经模拟消化后, 其活性物质 含量没有显著变化。体外抗氧化实验 ABTS、 DPPH 和 FRAP 结果均表明, 黑苦菾米黄酮具有 抗氧化活性，体外模拟消化后，其抗氧化活性有 所降低; 细胞 ROS 结果表明, 黑苦荞米黄酮模 拟消化前后均具有较好的 ROS 抑制活性。进一 步研究表明, 黑苦菾米黄酮模拟消化前后对 $\alpha$ 葡萄糖苷酶具有较好的抑制能力，同时可以促进 细胞对葡萄糖的消耗以及细胞糖原的生成, 具有 较好的降血糖活性。

关键词: 黑苦荞米; 黄酮; 体外模拟消化; 抗氧化; 降血糖 